\title{
ETNOCONHECIMENTO DOS CONSUMIDORES DE PESCADO DA REGIÃO METROPOLITANA DE BELÉM, ESTADO DO PARÁ
}

\section{ETHNOKNOWLEDGE OF FISH CONSUMERS IN THE METROPOLITAN REGION OF BELÉM, PARÁ STATE}

Joane Natividade de Souza ${ }^{1 *}$, Renan Rocha de Almeida ${ }^{2}$, Ruth Helena Cristo Almeida ${ }^{3}$,

Rafael Anaisce das Chagas ${ }^{4} \&$ Ian Rocha de Almeida ${ }^{5}$

${ }^{1,2}$ Curso de Engenharia de Pesca, Universidade Federal Rural da Amazônia - UFRA

${ }^{3,4}$ Instituto Socioambiental e dos Recursos Hídricos, Universidade Federal Rural da Amazônia - UFRA

${ }^{5}$ Programa de Pós-graduação em Recursos Hídricos e Saneamento Ambiental, Universidade Federal Rio Grande do Sul - UFRS

*E-mail: joanenatividade@gmail.com

Recebido em 09/10/2021 - Publicado em 14/01/2022

RESUMO O objetivo geral deste presente trabalho é discutir e analisar quais critérios são adotados para o consumo de pescado na Região Metropolitana de Belém, estado do Pará (RMB), por meio da análise do perfil socioeconômico do consumidor, origem dos seus conhecimentos a respeito do tema e suas preferências no que se diz respeito a seus hábitos de compra e consumo de pescado, com base nas respostas obtidas através de questionário. A metodologia consistiu na aplicação de questionário, através da plataforma Google Forms, apresentando 16 perguntas relacionadas às questões abordadas nesse trabalho, sendo aplicada nos municípios Ananindeua, Belém, Benevides, Castanhal, Marituba, Santa Bárbara do Pará e Santa Isabel do Pará e contou com a participação de 239 pessoas. Quando perguntados sobre a preferência na escolha do pescado, a dourada apresenta $68 \%$ como espécie preferida para consumo nos municípios da RMB. A pesquisa mostra que o local de compra para consumo são as feiras do bairro, as quais apresentam 59\%. A maioria dos entrevistados prefere o pescado fresco $60,26 \%$, como forma de conservação mais procurada. Quanto ao motivo da escolha, a principal apontada foi o sabor, presente em $89 \%$ das entrevistas. Grande parte alegou que consumiria todos os tipos e pescado, por outro lado, o tamuatá, foi eleito o pescado que os entrevistados não comeriam, pelo fato de ser avistado em ambientes de pouca higiene, e apresentar sabor e odor forte. Quando perguntados como aprenderam a identificar o frescor do pescado, $67 \%$ dos entrevistados responderam que esse conhecimento veio através de ensinamento familiar, vivenciando que a preferência é uma questão pessoal e está relacionada com a tradição cultural do consumidor.

Palavras-chave: etnoconhecimento, saber popular, preferencias do consumidor.
ABSTRACT The aim of this work is to discuss and analyzing which criteria adopted for fish consumption in the Belém, Pará State, Metropolitan Region through the analysis of the consumer socioeconomic profile, the origin of his knowledge about the theme and his preferences about their fish buying and consumption habits, based on the answers obtained through a questionnaire. The methodology was the application of a questionnaire through the Google Forms platform, composed of 16 questions related to the themes addressed in this work directed to fish consumers in the municipalities of Ananindeua, Belém, Benevides, Castanhal, Marituba, Santa Bárbara do Pará and Santa Isabel do Pará. The questionnaire reached a total of 239 people. When asked about the preference in the choice of fish the dourada appears with about $68 \%$ as the preferred species for consumption in the BMR. The survey shows that most purchase places for consumption are the neighborhood fairs with $59 \%$ of the answers. Most respondents (about 60\%) prefer fresh fish as the most sought-after form of conservation. As to the reason for the choice, the main answer obtained was the taste present in $89 \%$ of the interviews. Many respondents claimed that they would consume all types of fish, on the other hand, Tamuatá was chosen as the fish that respondents would not eat because it was seen in poor hygiene environments and had a strong flavor and odor. When asked how they learned to identify the fish freshness, $67 \%$ of respondents answered that this knowledge came through family teaching, showing that preference is a personal question and is related to the consumer cultural tradition.

Key words: ethnoknowledge, popular knowledge, ponsumer preferences. 


\section{Introdução}

No princípio das sociedades primitivas e tradicionais existia uma ligação entre o homem e a natureza, tanto no campo das atividades do fazer, das técnicas e da produção, quanto no campo simbólico. É perceptível nas sociedades indígenas brasileiras, por exemplo, onde o tempo para pescar, caçar e plantar é marcado por mitos ancestrais, pelo aparecimento de constelações estelares no céu, por proibições e interdições (Diegues, 2001). Sendo assim transmitido de geração para geração de forma oral e cultural, esta prática é conhecida como etnoconhecimento. Esse conhecimento do saber repassado é descrito com alta relevância para a proteção dos recursos naturais, que inclui os recursos pesqueiros que o homem utiliza para a complementação alimentar (Diegues et al., 2000).

O pescado é um alimento com alto teor de proteínas e rico em vitaminas e minerais. A presença de vitaminas e minerais se dá, principalmente, por ser fonte de ácidos graxos essenciais n-3 eicosapentaenoico (EPA) e docosaexaenoico (DHA). O consumo desse alimento se associa à redução do risco de doenças cardiovasculares e a funções importantes nas fases iniciais do desenvolvimento humano (Sartori \& Amancio, 2012).

Em várias regiões do mundo, diversas espécies de peixe estão presentes na mesa do consumidor. $\mathrm{O}$ crescimento médio anual do consumo global de peixes é de 3,2\%, excede o crescimento populacional de 1,6\%, e excede o consumo total de carne bovina e suína $2,8 \%$, incluindo ovinos e outros. O consumo de pescado apenas não excede o consumo de aves que é de 4,9\%. Em uma base per capita, o consumo alimentar de peixes aumentou de 9,0 kg em 1961 para 20,2 kg em 2015, uma média de cerca de 1,5\% ao ano (FAO, 2018).

$\mathrm{O}$ consumo de pescado no Brasil é bastante variado e com grande potencial a ser desenvolvido: na região Norte, o Estado do Pará, apresenta consumo per capita de 18,69 kg/ano, enquanto a média brasileira está ao redor de $6 \mathrm{~kg} /$ per capita/ano, sendo inferior quando comparado a outros países (Embrapa, 2015). O consumo de pescado no Estado pode estar associado a fatores culturais adquiridos dos povos indígenas, à diversidade de espécies disponíveis e à variedade de receitas da gastronomia regional que tornam esse consumo maior que a média nacional (Mangas et al., 2016).

O Pará é uns dos principais estados exportadores de pescado. Em Belém, a maior parte é fornecida para as indústrias locais que se concentram no processamento e comercialização atendendo o mercado nacional e internacional (Lopes et al., 2020). A comercialização do pescado na Região Metropolitana de Belém é realizada, principalmente, nas feiras e nos mercados municipais, apesar de não apresentar condições de infraestrutura e higiene ideais, o que resulta por influenciar na qualidade do pescado (Lopes et al., 2020).

No Brasil, a carne de peixe ainda é pouco consumida se compararmos com outros países, como o Japão e a China, sendo o fator cultural determinante para o consumo (Peixe BR, 2019). O preço elevado e falta de hábito podem ser fatores determinantes na escolha do consumidor brasileiro, tendo em vista que se faz necessário o desenvolvimento de tecnologias que tornem mais prático o consumo de peixe uma vez que o rápido processo de deterioração e o odor característico de peixe na geladeira reduzem a aquisição desta carne pelo consumidor (Guimarães et al., 2020).

Existem diversas tecnologias para impedir a rápida deterioração da carne do peixe, esse produto é submetido a conservação e processamento como congelamento, filetagem, salga e outros, que pode aumentar a durabilidade dessa carne agregando valor ao produto passando a ter um maior tempo de vida útil (Argenta, 2012). O consumidor, por sua vez tem formas distintas de verificar o estado de frescor e de deterioração do produto, esse conhecimento popular pode ser adquirido de maneira acadêmica, por capacitações e pesquisas, ou repassado de geração para geração por seus ancestrais.

Portanto, é necessário analisar o mercado interno para se obter maior entendimento sobre as preferências do consumidor, com a evidência de grande diversidade de fatores sociais, culturais e econômicos que influenciam o consumo do pescado no Brasil, a fim de criar estratégias que busquem a popularização e aumento do consumo desses produtos, além da agregação de valor e melhorar a rentabilidade das empresas.

\section{Material e Métodos}

\section{ÁREA DE ESTUDO}

O trabalho foi conduzido na Região Metropolitana de Belém (RMB), composta por sete municípios do estado do Pará: Ananindeua, Benevides, Belém, Castanhal, Marituba, Santa Bárbara do Pará e Santa Izabel do Pará (Figura 1). 


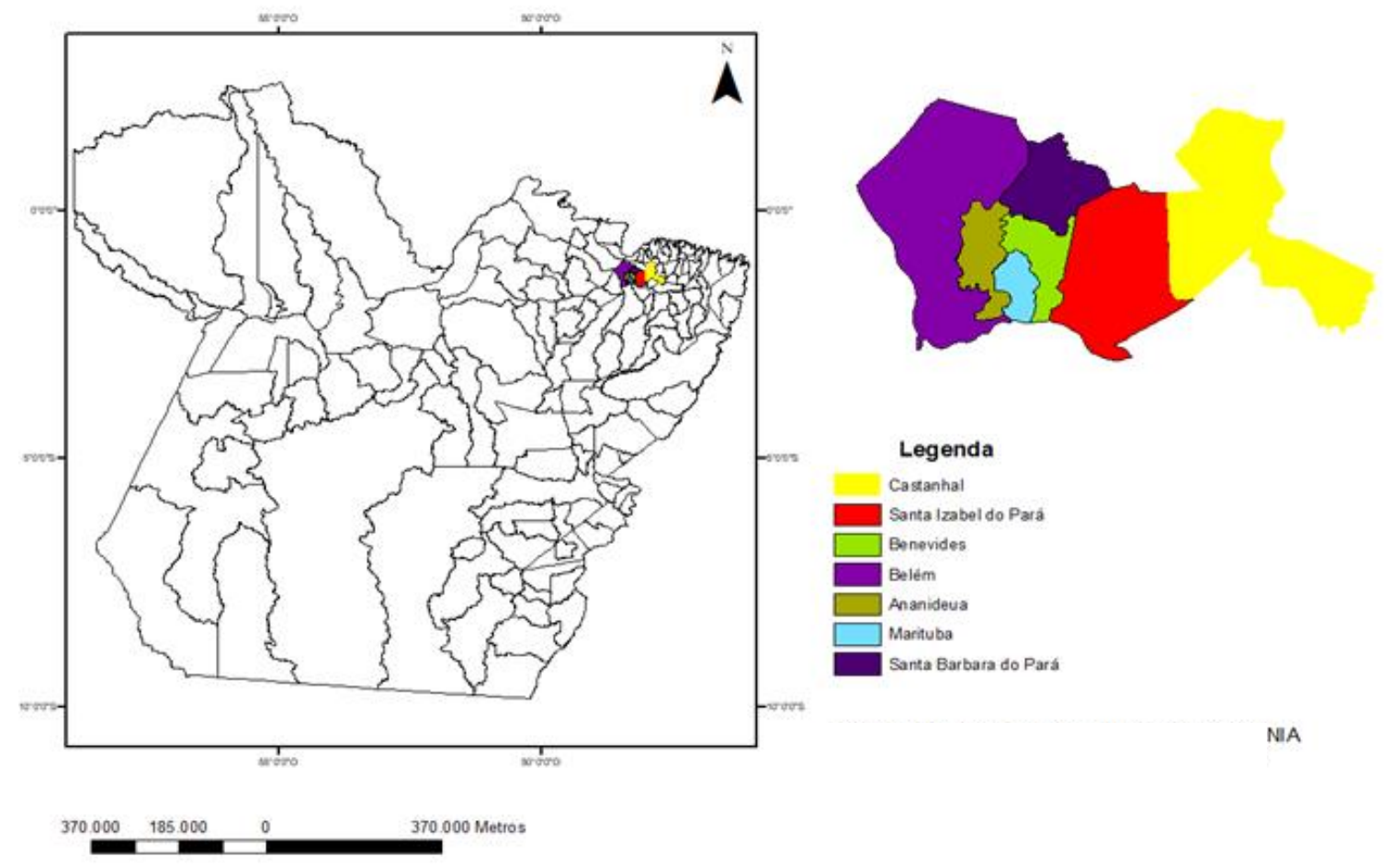

Figura 1. Mapa de localização da área de estudo: municípios da região Metropolitana de Belém.

\section{OBTENÇÃO DE DADOS}

Para obter dados foi realizado um levantamento de dados do tipo não supervisionado (quando não há entrevistador no local). Foi elaborado um questionário pela plataforma Google Forms (Apêndice - A).

\section{METODOLOGIA}

O formulário foi aplicado, no período de 17 de fevereiro de 2021 a 2 de março de 2021 , contendo ao todo 16 perguntas específicas a respeito do tema deste trabalho, a maioria das questões continha o uso de alternativas de resposta, ao invés do uso de questões abertas, que tem as vantagens de mais fácil entendimento para coleta e agrupamento das variáveis e maior rapidez no preenchimento. O questionário foi disponibilizado através de link com uma mensagem explicando o propósito da pesquisa e distribuído por meio das redes sociais para que possa atingir o maior número de pessoas.

\section{ANÁLISE DE DADOS}

Ao todo foram obtidas 239 respostas com a aplicação do questionário. Os participantes dos municípios da RMB ao serem perguntados onde possuem residência, obtiveram-se os municípios de Ananindeua (17.99\%), Belém (73,22\%), Benevides (1,67\%), Castanhal (4,18\%), Marituba (1,26\%) e Santa Isabel do Pará (1,67\%,), apenas o município de Santa Bárbara do Pará não obteve participantes. A análise foi feita a partir dos dados respondidos no formulário, onde foram obtidas informações especificas. Os dados foram exportados para uma planilha eletrônica do Microsoft Excel $^{\odot}$, onde serão analisados e, posteriormente, foram confeccionados gráficos e tabelas para apresentar os resultados da pesquisa.

\section{Resultados e Discussão}

\section{PERFIL SOCIOECONÔMICO DE PESCADO DA REGĩ̃o METROPOLITANA DE BELÉM - RMB}

No município de Belém, a maioria dos participantes reside no bairro da Cremação $13,14 \%$, seguido de Batista Campos 8,57\%, Jurunas 8\%, Icoaraci 6,86\%, Marco 6,86\% e Tenoné 6,29\%, o restante ficou abaixo de $5 \%$.

Com relação a Benevides, $100 \%$ das respostas para o bairro do centro, em Ananindeua a maioria respondeu Coqueiro 37,21\%, seguido de Cidade nova 20,93\%, o restante dos bairros respondidos foram respostas abaixo de 5\%. No município de Castanhal, a maioria dos participantes reside no bairro de Santa Lídia 30\%, seguido 
do bairro do Cristo $20 \%$. No município de Santa Isabel do Pará, a maioria dos participantes reside no bairro de Jardim Mirair 50\%, seguido dos bairros de Trevo e Mirante com 25\% cada.

Do total, 53\% ( $\mathrm{N}=129)$ dos entrevistados eram do sexo feminino e $45 \%(\mathrm{~N}=109)$ masculino. As idades dos que participaram do questionário foram variadas, por isso foi dividido em grupos de faixas etárias. A faixa mais representativa no questionário foi a de 20 - 24 anos, com $29,7 \%$ dos entrevistados, seguida por 25 - 29 anos (14,2\%), 15 - 19 anos (10,9\%), as demais faixas ficaram abaixo de 10\%. A idade é de suma importância para o direcionamento de estratégias de marketing, já que os desejos e as necessidades mudam de acordo com a idade, portanto, identificar a faixa etária dos consumidores pode ser um fator determinante na decisão de compra de determinados produtos (Kotler, 1994).

Ao avaliar as respostas no quesito escolaridade, pode-se notar que a maioria dos entrevistados apresentou ensino superior completo (37\%), como mostra a Figura 2. Se faz importante a análise desse quesito, visto que, o nível de escolaridade dos participantes pode interferir na preferência perante a escolha do consumo de determinado pescado, forma de conservação e tecnologias, pois teoricamente quanto maior o grau de escolaridade, mais informação a pessoa adquire.
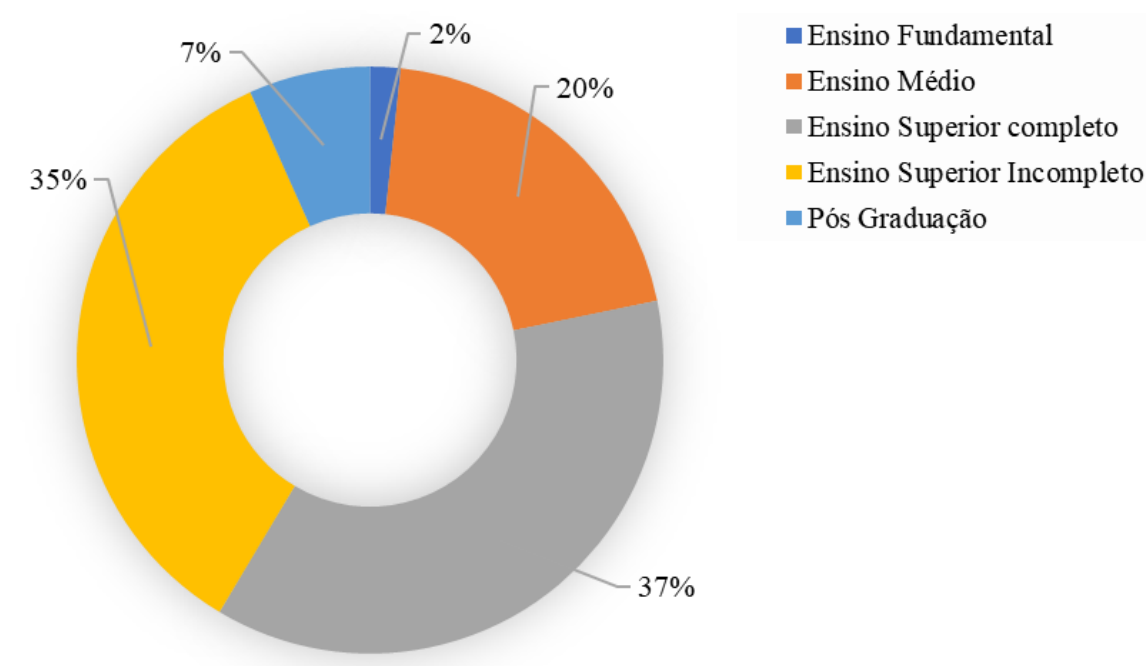

Figura 2. Grau de escolaridade dos consumidores de pescado da Região Metropolitana de Belém.

A maioria dos entrevistados possui graduação, o que traz compatibilidade com os resultados discutidos mais adiante, permitindo uma relação entre a escolha por determinado pescado e seu modo de apresentação.

No que se refere a renda familiar, a maioria apresenta uma renda acima de três salários-mínimos (52\%), como podemos perceber na Figura 3. Quanto ao número de pessoas que residem no mesmo domicílio, constatou-se que $28 \%$ têm até três membros, $10 \%$ residem sozinho, e $14 \%$ têm até cinco membros.
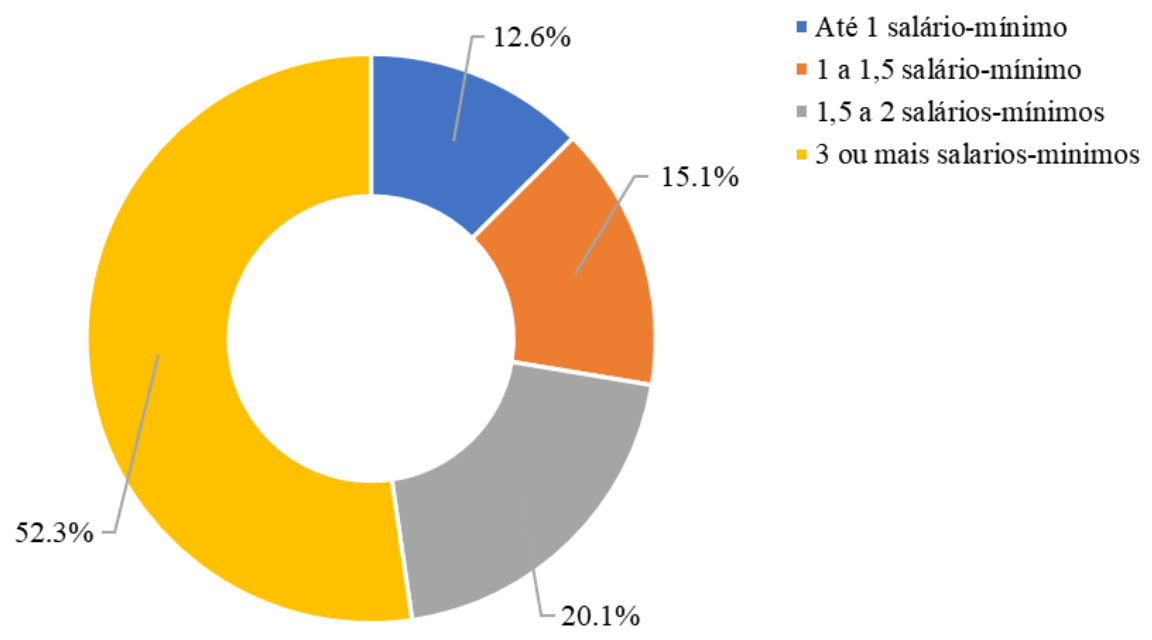

Figura 3. Renda mensal dos entrevistados. 


\section{PREFERÊNCIA DO CONSUMIDOR}

Quanto a preferência do consumidor, foram feitas perguntas em relação ao motivo da escolha por determinado pescado, local de compra, fatores que influenciam a compra, formas de preparo do produto, tipo de corte consumido e o local de consumo.

Quando indagados sobre a preferência na escolha, a dourada aparece em 68,6\% das entrevistas como espécie preferida para consumo nos municípios RMB (Tabela 1). Observamos que a escolha se deu pelo sabor de sua carne, pelo baixo nível de gordura. A pescada-gó aparece como a segunda espécie preferida, em 52\% das entrevistas, seguida pelo camarão regional e o caranguejo, com um pouco mais de $49 \%$, o camarão rosa aparece em $43 \%$, essas espécies se destacam como preferência de consumo, pois são espécies encontradas facilmente em supermercados, restaurantes e feiras.

Tabela 1. Distribuição das preferências de espécie de pescado para alimentação dos consumidores da região metropolitana de Belém.

\begin{tabular}{lcc}
\hline \multicolumn{1}{c}{ Espécie } & Nome científico & $\%$ \\
\hline Dourada & Brachyplatystoma flavicans & 68,60 \\
Pescada-gó & Macrodon ancylodon & 52,70 \\
Camarão regional & Macrobrachium amazonicum & 49,80 \\
Caranguejo & Ucides cordatus & 49,40 \\
Camarão-rosa & Farfantepenaeus subtilis & 43,50 \\
Pescada-amarela & Cynoscion acoupa & 43,10 \\
Tambaqui & Colossoma macropomum & 41,00 \\
Filhote & Brachyplatystoma filamentosum & 36,00 \\
Pirarucu & Arapaima gigas & 31,40 \\
Pescada-branca & Plagioscion squamosissimus & 24,30 \\
Mapará & Hypophthalmus spp. & 2,10 \\
Tainha & Mugil cephalus & 1,30 \\
Piramutaba & Brachyplatystoma vaillantii & 1,30 \\
\hline
\end{tabular}

O pescado ofertado nas em feiras do bairro e supermercado, constataram que a justificativa para a escolha quanto ao tipo de pescado comercializado pode estar relacionada justamente com o preço mais acessível. Ficou evidente, que a forma de armazenamento e comercialização pode ser um diferencial na preferência do consumidor em adquirir o pescado.

Entre homens e mulheres que participaram da entrevista, não houve diferença significativa entre as espécies preferidas. Além dessas, outras espécies foram citadas pelos entrevistados, como pratiqueira, anchova, cambéua, tucunaré, sardinha, bagre, salmão dentre outras, todas com $0,4 \%$.

Os entrevistados foram questionados sobre qual pescado não consumiria, 44,35\% afirmam que consumiriam todos os tipos de pescado, tamuatá lidera a lista de rejeição, com 9\%, (Tabela 2).

Dentre os motivos apresentados para o não consumo de determinada espécie, se destaca o sabor com $42,86 \%$, dos entrevistados $21,05 \%$ não souberam especificar um motivo, alergia aparece com 9,02\% dos motivos, seguido por aparência 7,52\%, a opção "vive na vala" apareceu com 6,02\%, odor/sabor forte conhecido na nossa região como "pitiú" e "remoso" aparecem empatados com 5,26\%, (Tabela 3).

Silva (2007), constatou que os tabus alimentares estão associados as crenças dos mitos de criação indígenas, categorizar um animal como reimoso ou não, está relacionado com seus atributos físicos. Para consumo o termo pitiú se associa a paladar, aparência e/ou cheiro desagradável.

Dentre as espécies, se destacam as cinco mais rejeitadas: tamuatá 9,62\%, camarão 7,11\%, pirarucu 5,44\%, caranguejo 5,02\% e bacalhau 2,09\%, cada um tem os seus motivos específicos (Tabela 4).

Quanto ao motivo da escolha, a principal apontada foi o sabor, presente em $89 \%$ das entrevistas, o preço aparece em $51 \%$ se destacando como o segundo maior motivo. Com isso, podemos afirmar que a dourada é a espécie preferida pelos consumidores da RMB, o motivo dessa escolha está relacionado ao seu sabor, que agrada a maioria dos entrevistados e ao seu preço acessível.

Segundo Gracia \& Albisu (2001), a qualidade é de suma importância, uma vez que o mercado global está cada vez mais exigente, por isso, as investigações acerca dos fatores responsáveis pela opção ou rejeição por determinados alimentos comprovam que o preço não é a única ligação direta e exclusiva com a opção do consumidor. 
Tabela 2. Pescado que não iriam ser consumidos pelos entrevistados da região metropolitana de Belém

\begin{tabular}{lc}
\hline \multicolumn{1}{c}{ Espécie } & \% \\
\hline Consumiria todos & 44,35 \\
Arraia & 0,42 \\
Aruanã & 0,84 \\
Atum & 0,84 \\
Bacalhau & 2,09 \\
Baiacu & 1,67 \\
Bandeirada & 2,09 \\
Bodó & 0,42 \\
Cação & 0,42 \\
Camarão & 7,11 \\
Caranguejo & 5,02 \\
Curimatã & 0,42 \\
Dourada & 0,42 \\
Filhote & 0,84 \\
Golfinho e Boto-rosa & 0,42 \\
Gurijuba & 1,26 \\
Lagosta & 0,42 \\
Mapará & 1,67 \\
Mexilhão & 1,26 \\
Ostra & 1,26 \\
Peixe de carne escura & 0,42 \\
Peixe de pele & 0,84 \\
Pescada-amarela & 0,42 \\
Pescada-branca & 1,26 \\
Piramutaba & 0,42 \\
Pirarucu & 5,44 \\
Polvo & 0,84 \\
Sarda & 0,84 \\
Siri & 0,84 \\
Tambaqui & 2,09 \\
Tamoatá & 9,62 \\
Tilápia & 0,84 \\
Tucunaré & 0,42 \\
Sardinha & 0,84 \\
Xáreu & 0,42 \\
\hline & 0,84 \\
\hline
\end{tabular}

Tabela 3. Motivo para não comer o pescado

\begin{tabular}{lcc}
\hline & Motivo & \% \\
\hline Alergia & 9,02 \\
Aparência & 7,52 \\
Espinhas & 2,26 \\
Preparo & 0,75 \\
Remoso & 5,26 \\
Sabor & 42,86 \\
Odor/Sabor Forte (Pitiú) & 5,26 \\
Vive na vala & 6,02 \\
Não especificado & 21,05 \\
\hline
\end{tabular}

Tabela 4. Motivos pelos quais o pescado não seria consumido pelos entrevistados da região metropolitana de Belém

\begin{tabular}{lc}
\hline \multicolumn{1}{c}{ Espécie } & Motivo \\
\hline Tamoatá & Sabor, Aparência, Local que vive e Sabor/Odor "pitiú" \\
Camarão & Alergia e Sabor \\
Pirarucu & Sabor e odor forte \\
Caranguejo & Alergia e Sabor \\
Bacalhau & Sabor e odor forte \\
\hline
\end{tabular}




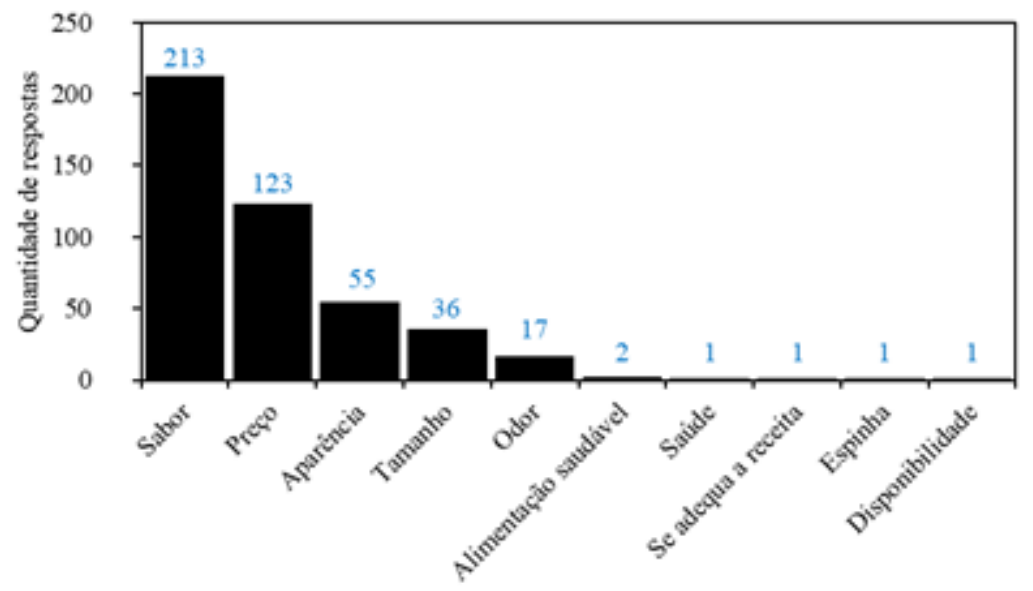

Figura 4. Motivação para a escolha do pescado pelos consumidores

Quando se faz a relação entre renda familiar e motivação de escolha, podemos perceber que quanto maior o poder aquisitivo maior é a tendência em optar pelo sabor. Podemos observar também, que as pessoas que tem a renda entre 1,5 a 2 salários mínimos, prezam pelo custo benefício na hora da escolha (Tabela 5).

Tabela 5. Comparação entre renda familiar e motivação da escolha pelo pescado.

\begin{tabular}{lcc}
\hline \multicolumn{1}{c}{ Renda } & Sabor $\mathbf{( \% )}$ & Preço $(\%)$ \\
\hline Até 1 salário-mínimo & 83,33 & 50,00 \\
1 a 1,5 salário-mínimo & 88,89 & 58,33 \\
1,5 a 2 salários-mínimos & 91,67 & 70,83 \\
3 ou mais salários-mínimos & 92,00 & 40,80 \\
\hline
\end{tabular}

A pesquisa mostra que o local de compra para consumo são as feiras do bairro e supermercados, presentes em $32 \%$ e $30 \%$ das entrevistas respectivamente, indicando locais de praticidades e fácil acesso, como mostra a Figura 5.

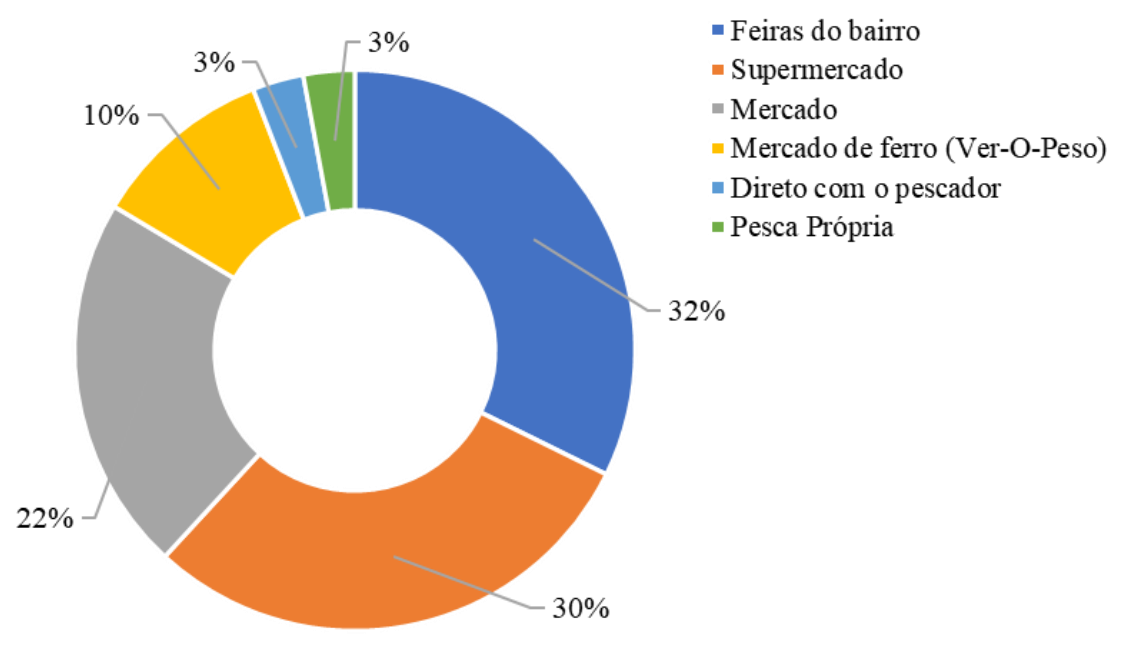

Figura 5. Local de compra do pescado pelos consumidores

Segundo Mangas et al. (2016), apesar da tendência e do crescimento das vendas de pescado nos supermercados, a disposição para consumo em feiras livres, pode estar relacionado a fatores culturais.

Quando perguntado se há um costume de comprar sempre no mesmo local, $82 \%$ dos entrevistados responderam que sim, como representa na Figura 6, indicando fidelidade e confiança no local de compra, além de serem locais de fácil acesso e praticidade do dia a dia. 


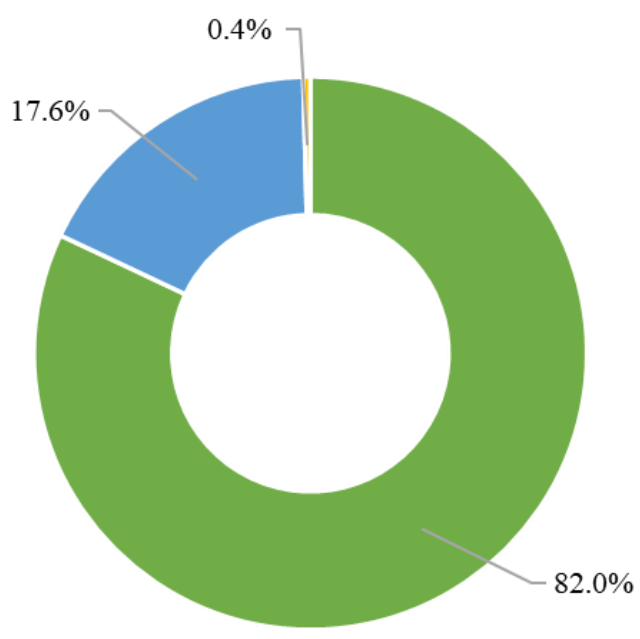

$\square \operatorname{Sim}$

- Não

Em lugares diversos

Figura 6. Compra no mesmo local.

A maioria dos entrevistados prefere o pescado fresco $(60,26 \%)$ como forma de conservação mais procurada, a pesquisa permite relacionar a preferência de conservação com o local mais procurado pelo consumidor, que são as feiras dos bairros, pois normalmente nas feiras o pescado é comercializado fresco.

Podemos também relacionar o pescado congelado, que aparece na pesquisa com $28 \%$, com o segundo local mais procurando para consumo, os supermercados, uma vez que essa é a forma de conservação mais encontrada no local, Figura 7.

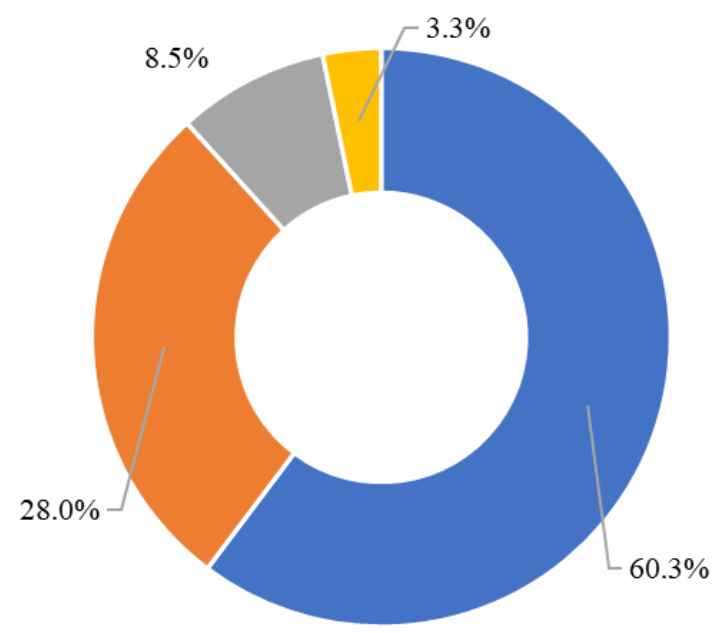

\author{
- Pescado fresco \\ - Pescado congelado \\ - Pescado em Salga \\ Em conserva (enlatado)
}

Figura 7. Forma de conservação do pescado

Normalmente o pescado é comercializado in natura inteiro, com o processamento resumindo-se a evisceração e retirada da cabeça, seguido de posteamento ou evisceração seguido de filetagem, posteriormente essas variações de processamento são submetidas a resfriamento em gelo ou sistema de frio apropriado ou congelamento em câmaras próprias (Lopes et al., 2020).

Fazendo uma relação entre motivação de escolha e a forma de conservação para consumo, podemos perceber que o pescado fresco é comercializado, geralmente, com preços mais baixos.

A preferência pelo pescado fresco in natura é uma questão pessoal e está relacionada com a tradição cultural do consumidor de escolher o melhor modo de preparo de seu alimento (Lopes et al., 2020).

Os entrevistados da RMB opinaram sobre a forma do pescado considerada a ideal para o dia a dia, o filé foi a forma considerada de mais praticidade, $47 \%$ seguido pela posta com $35 \%$ e espalmado com $11 \%$, Figura 8 , ressaltando a escolha do consumidor pela praticidade e facilidade na busca de locais próximo a sua residência, feiras do bairro, e supermercado, como já apresentado. 
Os consumidores da RMB, elegeram a altos preços (51\%) como a principal dificuldade para o consumo do pescado, seguido por aparência e condições do local escolhido $(27 \%)$ e a qualidade do produto $(12,55 \%)$ como podemos ver mais detalhadamente na Figura 9.

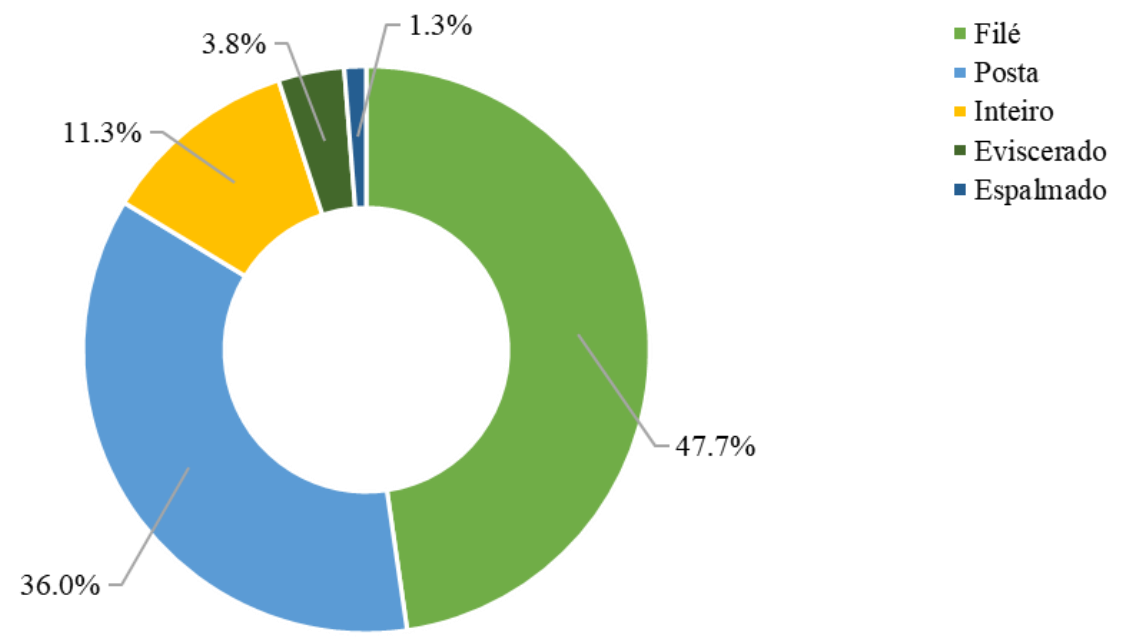

Figura 8. Forma do pescado considerado de mais praticidade para o dia a dia pelos consumidores

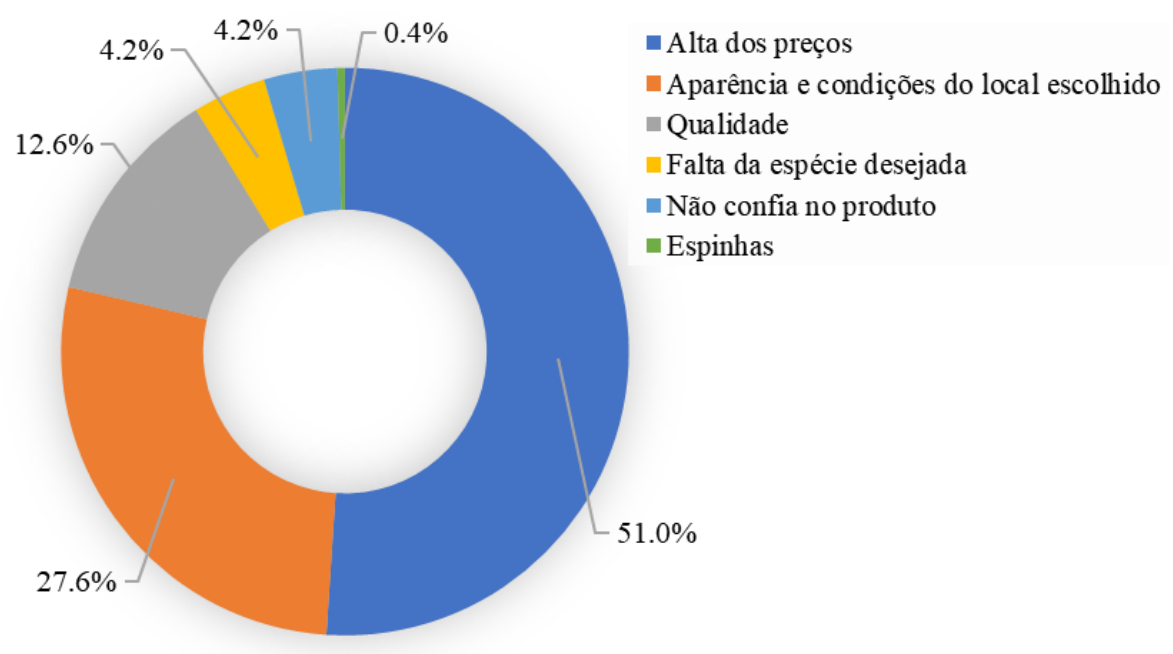

Figura 9. Principais dificuldades encontradas no mercado de pescado

O preço tem papel importante na escolha do produto. Além de o consumidor preferir comprar em mercados que, em média, apresentam preços mais baixos, o consumidor também tende a ter preferência pelas espécies de pescado mais baratas, no caso dos peixes, como citado, a dourada (Lopes et al., 2020).

Quanto ao local escolhido reforça a ideia de que o consumidor costuma buscar sempre no mesmo local de sua preferência, por já estar acostumado com o preço e condições do local. O conhecimento de atributos desses produtos que formam a preferência do consumidor devem ser alvo para que empresas desenvolvam estratégias de comercialização, garantindo a sustentabilidade e competitividade das cadeias de produção (Soares \& Belo, 2015).

Existem vários fatores que influenciam na escolha do pescado, dentre eles o mais importante é a qualidade, que geralmente e avaliada pelos consumidores com uma rigorosidade ainda maior do que muitos outros alimentos, pois estes devem estar sempre frescos e com uma boa aparência (Lopes et al., 2020).

\section{CONHECIMENTO DO CONSUMIDOR}

Quando indagados sobre como os entrevistados definem se o pescado está em condições para o consumo, se obteve como resposta a condição da textura da carne, $60 \%$ das respostas como o primeiro método de análise. Os segundos métodos de análise são: aparência do globo ocular e aparência do opérculo, ambas com 51\%, Figura 10. 


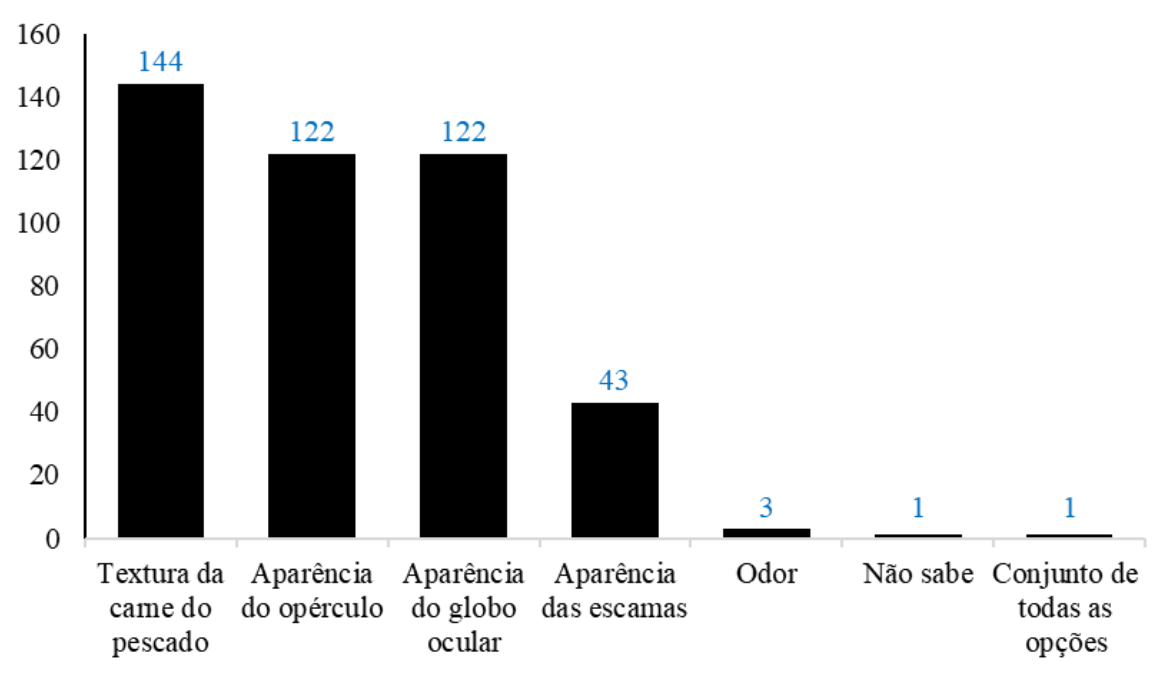

Figura 10. Como o consumidor define se o pescado está fresco.

O etnoconhecimento é bastante presente em toda sociedade, carregando histórias, culturas de raízes profundas que são passadas de geração para geração, pois é através dessas informações que percebemos as similaridades entre o conhecimento científico e o conhecimento empírico (Mello, 2013).

O conhecimento popular sobre a escolha e determinação do pescado próprio para consumo, que pode ser identificado a olho nu, deve apresentar características de carne firme, que quando pressionada retorna ao estado inicial, a cavidade ocular preenchida, olhos são brilhantes e salientes, o opérculo deve estar bem vermelho, as escamas do peixe fresco estão sempre bem firmes e resistentes.

Na pesquisa, menos de $1 \%$ dos entrevistados não sabiam identificar o frescor do pescado. Segundo a Organização das Nações Unidas para a Alimentação e a Agricultura FAO (1998), os métodos sensoriais devem ser ensinados, como uma disciplina científica, utilizada para evocar, medir, analisar e interpretar reações características dos alimentos, percebidas por meio dos sentidos da visão, olfato, paladar, tato e audição. São as formas mais eficazes de reconhecer um peixe em mau estado.

Quando perguntados como aprenderam a identificar o frescor do pescado, 67\% dos entrevistados responderam que esse conhecimento veio através de ensinamento familiar, e $18 \%$ dos entrevistados responderam que esse conhecimento veio através da universidade, como podemos analisar na Figura 11.

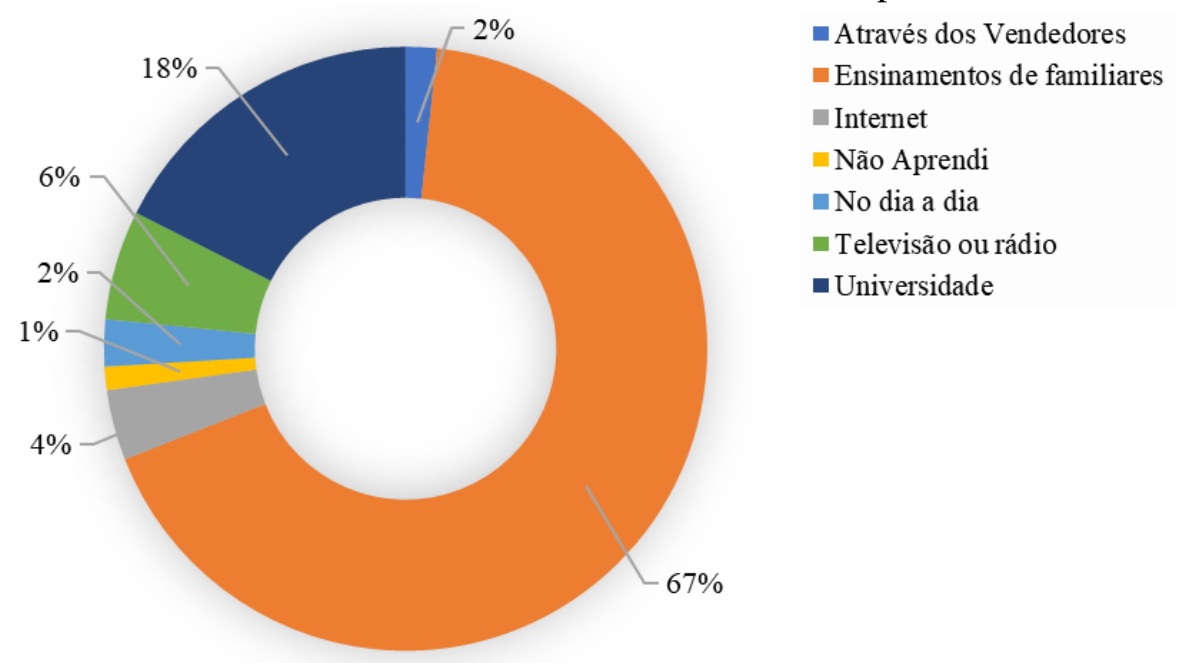

Figura 11. Como o consumidor aprendeu a identificar o estado de conservação do pescado

A forma como o consumidor da RMB escolhe e identifica o frescor do pescado, está relacionada com a tradição de ensinamentos familiares, onde se aprende em casa e repassa esse conhecimento adiante, de geração para geração, tornando assim, em uma prática tradicional. 


\section{Conclusões}

A partir das análises dos dados, é possível afirmar que os objetivos da pesquisa foram alcançados. Os consumidores da RMB escolhem o seu pescado pelo sabor da carne, porém o preço também é um quesito importante. Outro ponto importante que pôde ser observado é a relevância a escolha de locais de praticidades e fácil acesso, como as feiras de bairro que se destacam pela proximidade, o que afeta na preferência por pescado fresco, pois é mais encontrado nessas feiras. Porém também se percebe uma relevância na preferência por pescado congelado, que por sua vez, são mais encontrados em supermercados. Foi perceptível que os entrevistados costumam comprar no mesmo local, demonstrando assim fidelidade e confiança no produto ofertado.

Deve levar em consideração a forma de filé que é apontada como forma de mais praticidade do dia a dia, reforçando a ideia que o consumidor opta por método rápido e prático de preparo, assim como a posta, que ficou em segundo nessa preferência. Podemos afirmar que essas formas de preparo se dão em virtude de comidas muito apreciadas pelos consumidores, que seriam o filé de peixe frito e caldeirada (posta). A dourada é o pescado preferido pelos entrevistados.

Portanto, nessa pesquisa é possível dizer que o conhecimento sobre a forma de conservação do pescado é, em sua maioria, repassado por seus familiares, de forma cultural e tradicional. A maioria dos entrevistados não consome tamuatá, pelo sabor/odor "pitiú", por já o ter avistado em regiões de esgoto e "vala" e pela sua aparência, porém é importante salientar que camarão e caranguejo têm alto grau de rejeição em virtude de alergia, pirarucu e bacalhau também são rejeitados em virtude do seu sabor e odor fortes.

\section{Referências}

Adams, C., \& Viertler, R.B. (1996). Caiçaras na Mata Atlântica: pesquisa científica versus planejamento e gestão ambiental. Universidade de São Paulo. São Paulo: Edusp.

Argenta, F.F. (2012). Tecnologia de pescado: características e processamento da matéria-prima. [Monografia] Faculdade de Veterinária. Porto Alegre, RS.

Córdula, E.B.L., \& Nascimento, G.C.C. (2014). Etnoconhecimento e a escola para um futuro sustentável. Revista Educação Pública, Rio de Janeiro, RJ. Disponível em: https://educacaopublica.cecierj.edu.br/ artigos/14/7/etnoconhecimento-e-a-escola-para-um-futuro-sustentaacutevel.

Diegues, A.C.S.A. (2001). Ecologia Humana e Planejamento Costeiro. São Paulo: Editora Hucitec: Brasil.

Diegues, A.C.S.A. (2001). O mito moderno da natureza intocada (vol. 4). São Paulo: Editora Hucitec.

Diegues, A.C.S.A., Arruda, R., Silva, V., Figols, F., \& Andrade, D. (2000). Saberes tradicionais e biodiversidade no Brasil. Biodiversidade e comunidades tradicionais no Brasil. São Paulo: Ministério do Meio ambiente, dos Recursos Hídricos e da Amazônia Legal/COBIO-Coordenadoria da Biodiversidade/NUPAUB-Núcleo de Pesquisas sobre Populações Humanas e Áreas Úmidas Brasileiras Universidade de São Paulo.

Embrapa - Empresa Brasileira de Pesquisa Agropecuária. (2015) A aquicultura e a atividade pesqueira. Disponível em: https://www.cnpma.embrapa.br/projetos/index.php3?sec.

FAO - Organização das Nações Unidas para Alimentação e Agricultura. (1998) Documento Técnico da Pesca da FAO. Disponível em: http://www.fao.org/3/V7180S/v7180s00.htm

FAO - Organização das Nações Unidas para Alimentação e Agricultura. (2018) The State of World Fisheries and Aquaculture 2018. Disponível em: http://www.fao.org/3/ca0191en/ca0191en.pdf

Gonçalvez, A., \& Passos, M.G. (2003). Uso da enzima transglutaminase na elaboração de um produto reestruturado à base de pescado. Revista Nacional da Carne, 28(317): 123-132.

Gracia, A., \& Albisu, L.M. (2001). Food consumption in the European Union: main determinants and country differences. Agribusiness: an international journal, 17(4): 469-488.

Guimarães, J.D.L.B., Calixto, F.A.A., de Moura Keller, L.A., Latini, J.T.P., Furtado, Â.A.L., \& de Mesquita, E.D.F.M. (2020). Alternativa tecnológica na utilização de peixe de baixo valor comercial oriundo da 
modalidade de pesca de arrasto: tira-vira percophis brasiliensis enlatado. Brazilian Journal of Development, 6(6): 38213-38230.

IBGE - Instituto Brasileiro de Geografia e Estatística (2010) Pesquisa de Orçamento Familiar (POF), 20082009. Disponível em: <http://www.sidra.ibge.gov. br>. Acesso em: 18 set. 2013.

IBGE - Instituto Brasileiro de Geografia e Estatística (2014) Estimativas populacionais dos municípios em 2014. Disponível em: https://www.ibge.gov.br/arquivo/noticias/pdf/analise_estimativas_2014.pdf

Jabbour, C.J.C. (2010). Tecnologias ambientais: em busca de um significado. Revista de Administração Pública, 44(3):591-611.

Kotler, P. (1994). Administração de marketing: análise, planejamento, implementação e controle. In: Administração de marketing: análise, planejamento, implementação e controle. São Paulo, Atlas. pp. 676676.

Lopes, L.R., da Silva, G.L.P., da Silva Gonçalves, M.L.N., Amin, M.M., \& da Silva, F.L. (2020). Dimensões associadas ao consumo de -na região metropolitana de Belém-PA. Contribuciones a las Ciencias Sociales, 68(junho): 1-19.

Mangas, F.P., Rebello, F.K., dos Santos, M.A.S., \& Martins, C.M. (2016). Caracterização do perfil dos consumidores de peixe no município de Belém, estado do Pará, Brasil. Revista em Agronegócio e Meio Ambiente, 9(4), 839-857.

Mello, L.C.D. (2013). Análise da produção científica brasileira sobre o conhecimento tradicional. [Dissertação de mestrado] Universidade Federal de São Carlos. São Carlos (São Paulo).

Mussy, J.H.A., Corrêa, A.C.D.S., Yokoyama, L.T., Silveira, E.L., Kietzer, K.S., \& Domingues, R.J.D.S. (2014). Cicatrização de ferimentos incisionais em ratos submetidos à alimentação com carne suína. Revista Paraense de Medicina, 28(3), 9-18.

Nascimento, G.C. (2013). Mestre dos mares: o saber do território, o território do saber na pesca artesanal. Cananéa, F.A. Sentidos de leitura: sociedade e educação. João Pessoa: Imprell, pp. 57-68.

Peixe BR - Associação Brasileira da Piscicultura. (2019) Anuário Peixe BR, 2018. Disponível em: https://www.peixebr.com.br/anuario2018/

Posey, D.A. (1987). Etnobiologia: teoria e prática. In: Ribeiro, B.G. Suma etnológica brasileira, 1:15-25.

Posey, D.A. (1996). Os povos tradicionais e a conservação da biodiversidade. Uma estratégia latinoamericana para a Amazônia. Semam 1: 149-157.

Sartori, A.G.O., \& Amancio, R.D. (2012). Pescado: importância nutricional e consumo no Brasil. Segurança alimentar e nutricional, 19(2), 83-93.

Silva, A.L.D. (2007). Comida de gente: preferências e tabus alimentares entre os ribeirinhos do Médio Rio Negro (Amazonas, Brasil). Revista de Antropologia, 50(1): 125-179.

Soares, L., \& Belo, M.A. (2015). Consumo de pescado no município de Porto Velho-RO. Enciclopédia Biosfera, 11(21):3059-3067. 